\title{
Different effects of amiodarone and dofetilide on the dispersion of repolarization between well-coupled ventricular and Purkinje fibers ${ }^{1}$
}

\author{
Tamás Árpádffy-Lovas, Zoltán Husti, István Baczkó, András Varró, and László Virág
}

\begin{abstract}
Increased transmural dispersion of repolarization is an established contributing factor to ventricular tachyarrhythmias. In this study, we evaluated the effect of chronic amiodarone treatment and acute administration of dofetilide in canine cardiac preparations containing electrotonically coupled Purkinje fibers (PFs) and ventricular muscle (VM) and compared the effects to those in uncoupled PF and VM preparations using the conventional microelectrode technique. Dispersion between PFs and VM was inferred from the difference in the respective action potential durations (APDs). In coupled preparations, amiodarone decreased the difference in APDs between PFs and VM, thus decreasing dispersion. In the same preparations, dofetilide increased the dispersion by causing a more pronounced prolongation in PFs. This prolongation was even more emphasized in uncoupled PF preparations, while the effect in VM was the same. In uncoupled preparations, amiodarone elicited no change on the difference in APDs. In conclusion, amiodarone decreased the dispersion between PFs and VM, while dofetilide increased it. The measured difference in APD between cardiac regions may be the affected by electrotonic coupling; thus, studying PFs and VM separately may lead to an over- or underestimation of dispersion.
\end{abstract}

Key words: dispersion of repolarization, chronic amiodarone, dofetilide, electrotonic coupling, cardiac Purkinje fibers.

Résumé : Il est établi que l'augmentation de la dispersion de la repolarisation à travers la paroi constitue un facteur contributif aux tachyarythmies ventriculaires. Dans cette étude, nous avons évalué l'effet de l'administration d'amiodarone à long terme et de l'administration aiguë de dofétilide dans des préparations canines de cœur contenant des fibres de Pukinje (FP) et du muscle ventriculaire (MV) couplés électrotoniquement, ainsi que comparé les effets à ceux de préparations de FP et de MV découplés, et ce, à l'aide de la technique de microélectrode classique. La dispersion entre les FP et le MV était déduite de la différence entre les durées des potentiels d'action (DPA) respectives. Dans les préparations couplées, l'amiodarone entraînait une diminution de la différence entre la DPA des FP et du MV, et donc une diminution de la dispersion. Dans les mêmes préparations, le dofétilide entraînait une augmentation de la dispersion par une prolongation plus marquée dans les FP. Cette prolongation était encore plus prononcée dans les préparations de FP découplées, tandis que l'effet était le même dans le MV. Dans les préparations découplées, l'amiodarone n'entraînait pas de changement dans la différence entre les DPA. En conclusion, l'amiodarone entraînait une diminution de la dispersion entre les FP et le MV, tandis que le dofétilide entraînait une augmentation de celle-ci. La différence mesurée entre la DPA des régions cardiaques pourrait être affectée par le couplage électrotonique; l'étude des FP et du MV séparément pourrait donc mener à une sous- ou une surestimation de la dispersion. [Traduit par la Rédaction]

Mots-clés : dispersion de la repolarisation, amiodarone à long terme, dofétilide, couplage électrotonique, fibres de Purkinje cardiaques.

\section{Introduction}

Dispersion of repolarization affects various mechanisms in cardiac arrhythmogenesis. Increased transmural dispersion is an established contributing factor to ventricular tachyarrhythmias (VTs), such as Torsades de Pointes arrhythmias (Antzelevitch et al. 1998). Transmural dispersion has been reduced by amiodarone ex vivo in canine wedge preparations (Sicouri et al. 1997) as well as human transmural slice preparations (Drouin et al. 1998).
In vivo, transmural dispersion is derived from QT/QTc or JTc dispersion in the ECG, which have all been decreased by chronic amiodarone in a clinical setting (Cui et al.1994, 1998), whilst dofetilide has increased global electrical heterogeneity (Stabenau et al. 2020).

Another region characterized by high dispersion is the junction between Purkinje fibers (PFs) and the ventricular myocardium (VM), also known as the Purkinje-muscle junction (PMJ). The PMJ has been described as a contributor to local heterogeneity

Received 29 April 2020. Accepted 26 June 2020.

T. Árpádffy-Lovas and Z. Husti. Department of Pharmacology and Pharmacotherapy, Faculty of Medicine, University of Szeged, Szeged, Hungary.

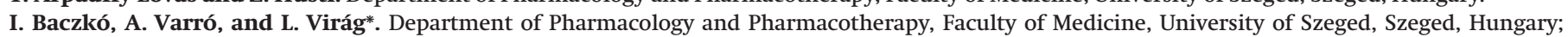

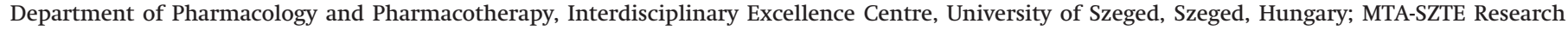
Group of Cardiovascular Pharmacology, Szeged, Hungary.

Corresponding author: András Varró (email: varro.andras@med.u-szeged.hu).

${ }^{1}$ This paper is part of a Special Issue of selected papers from the Joint North American/European IACS 2019.

*These authors share senior authorship.

Copyright remains with the author(s) or their institution(s). Permission for reuse (free in most cases) can be obtained from copyright.com. 
of ventricular action potential duration (APD) (Walton et al. 2014; Martinez et al. 2018). Based on this, if PF repolarization lengthening is markedly stronger than that of the surrounding VM at the PMJ, early afterdepolarization (EAD) may develop in PFs, which under certain conditions can evoke propagating extra beats in VM (Nattel and Quantz 1988; Varró et al. 1990). As such, PF repolarization lengthening can serve as a trigger for arrhythmias; in addition, increased dispersion of repolarization itself can also enhance the risk of tachyarrhythmia in the PMJ as a substrate for arrhythmia (Nogami 2011a, 2011b). While transmural dispersion may be directly measured ex vivo and closely estimated in vivo, studying the dispersion of repolarization between PFs and VM is currently only possible in preparations containing electrotonically well coupled PFs and VM. Studying the effects of antiarrhytmic agents or agent candidates in such preparations may be beneficial, since decreasing dispersion could be a valid goal. Screening for drug candidates that do not increase dispersion may also increase cardiac safety. Even though the general electrophysiological effects of dofetilide (selective $I_{\mathrm{Kr}}$ inhibitor) and amiodarone (complex mechanism) are well understood, their effect on the dispersion between PsF and VM may only be estimated based on measurements from individual, uncoupled preparations. The aim of this study was to assess the effects of these two widely used antiarrhythmic drugs with established class III actions in preparations containing well-coupled PFs and VM to uncover additional features of these agents in the context of local dispersion.

\section{Materials and methods}

\section{Animals}

All experiments were carried out in compliance with the Guide for the Care and Use of Laboratory Animals (USA NIH publication No. 85-23, revised 1996) and conformed to the Directive 2010/63/ EU of the European Parliament. The protocols have been approved by the Ethical Committee for the Protection of Animals in Research of the University of Szeged, Szeged, Hungary (approval No. I-74-24-2017) and by the Department of Animal Health and Food Control of the Ministry of Agriculture and Rural Development (authority approval No. XIII/3331/2017).

\section{Conventional microelectrode technique}

Action potentials were recorded in preparations containing both electrotonically coupled subendocardial VM and PFs and in preparations in which VM and PF had been cut out separately (uncoupled preparations) obtained from the left ventricle and right ventricle of dogs using conventional microelectrode technique. Beagle dogs, either untreated or orally treated with amiodarone (50 mg $\cdot \mathrm{kg}^{-1} \cdot \mathrm{day}^{-1}, 4$ weeks), of either sex weighing 10-15 $\mathrm{kg}$ were sacrificed (sodium pentobarbital, $30 \mathrm{mg} / \mathrm{kg}$ administered intravenously) after an intravenous injection of $400 \mathrm{U} / \mathrm{kg}$ heparin. Then the heart of each animal was rapidly removed through a right lateral thoracotomy. The heart was immediately rinsed in oxygenated modified Locke's solution containing (in millimoles per litre): $\mathrm{NaCl} 128.3, \mathrm{KCl} 4, \mathrm{CaCl}_{2} 1.8, \mathrm{MgCl}_{2} 0.42, \mathrm{NaHCO}_{3} 21.4$, and glucose 10 . The $\mathrm{pH}$ of this solution was set between 7.35 and 7.4 when gassed with the mixture of $95 \% \mathrm{O}_{2}$ and $5 \% \mathrm{CO}_{2}$ at $37{ }^{\circ} \mathrm{C}$.

Preparations, containing free-running PFs and VM 25-35 mm in diameter and $2-4 \mathrm{~mm}$ in thickness (electrotonically coupled preparations from the left ventricle) (Figs. 1A-1C) and individual PFs (Fig. 1E) with small muscle endings and individual papillary VM (Figs. 1D, electrotonically uncoupled preparations from both of the left and right ventricle) were obtained and individually mounted in a tissue chamber with a volume of $50 \mathrm{~mL}$. Electrotonically coupled preparations were paced from a PF, mimicking physiological cardiac conduction. Stimulation was executed using a pair of platinum electrodes in contact with the preparation using rectangular current pulses of 0.5-2 ms duration. These stimuli were delivered at a constant cycle length of $1000 \mathrm{~ms}$ for at least 60 min allowing the preparation to equilibrate before the measurements were initiated. Transmembrane potentials were simultaneously recorded from PF and subendocardial VM using conventional glass microelectrodes (Fig. 1) filled with $3 \mathrm{~mol} / \mathrm{L} \mathrm{KCl}$ and having tip resistances of 5-20 $\mathrm{M} \Omega$ connected to the input of a high-impedance electrometer (Experimetria, type 309, Budapest, Hungary), which was coupled to a dual-beam oscilloscope. The resting potential (RP), action potential amplitude (APA), maximum upstroke velocity $\left(V_{\max }\right)$, and APD measured at $50 \%$ and $90 \%$ of repolarization $\left(\mathrm{APD}_{50}\right.$ and $\mathrm{APD}_{90}$, respectively) were online monitored and offline recorded using a home-made software (APES) running on a computer equipped with an ADA 3300 analog-to-digital data acquisition board (Real Time Devices, Inc., State College, Pennsylvania) having a maximum sampling frequency of $40 \mathrm{kHz}$. Dispersion of repolarization was inferred from the difference of $\mathrm{APD}_{90}$ values of $\mathrm{PFs}$ and $\mathrm{VM}$, referred to as $\triangle \mathrm{APD}_{90}$. Stimulation with a constant cycle length of $1000 \mathrm{~ms}$ was applied in the course of all experiments. Attempts were made to maintain the same impalement throughout each experiment. In case an impalement became dislodged, adjustment was attempted, and if the action potential characteristics of the reestablished impalement deviated by less than $5 \%$ from the previous measurement, the experiment continued (Lengyel et al. 2001; Jost et al. 2005; Orvos et al. 2015, 2019). All measurements were carried out at $37^{\circ} \mathrm{C}$.

\section{Statistical analysis}

All data are expressed as means \pm SEM. The " $n$ " number refers to the number of experiments. Depending on the type of comparison, Student's $t$ test was used either for independent samples (amiodarone) or for paired samples (dofetilide). The results were considered statistically significant when $p$ was $<0.05$.

\section{Results}

Comparison of baseline electrophysiology of electrotonically coupled and uncoupled preparations

In electrotonically coupled control preparations (Tables 1 and 2; Figs. 2A and $3 \mathrm{~A}$ ) most action potential characteristics both of $\mathrm{PF}$ and $\mathrm{VM}$ were comparable to those of individual $\mathrm{PF}$ and $\mathrm{VM}$ (uncoupled) preparations ( $n=21$ ) (Tables 3 and 4; Figs. 2C and 3C). VM APD was slightly longer in coupled preparations compared to the uncoupled preparations (Tables 3 and 4; Figs. 2C and 3C), while PF APD was slightly shorter in coupled preparations. APA, $V_{\max }$, and RP were similar to those of uncoupled (individual) preparations. Baseline dispersion $\left(\triangle \mathrm{APD}_{90}\right)$ was $39.6 \pm 4.0 \mathrm{~ms}$ (pooled controls, $n=21$ ) in coupled control groups of the drug studies. Conduction time (CT) to PFs was shorter in all preparations than that of VM, confirming an anterograde wave of depolarization. Since individual, electrotonically uncoupled PF and VM preparations were not necessarily taken from the same heart and were not in connection, differences in their APD cannot be directly measured, but average values showed an APD difference of $72.8 \mathrm{~ms}$ between the two groups of preparations under control circumstances (pooled controls, $n=13$ and 16).

\section{Effects of amiodarone}

Electrotonically coupled preparations obtained from animals after chronic amiodarone treatment $(n=11)$ did not show statistically significant changes in the RP, APA, and $V_{\max }$. Amiodarone treatment increased $\mathrm{APD}_{90}$ and $\mathrm{APD}_{75}$ values of PF potentials $(p<$ 0.01) (Table 1; Fig. 2B) while eliciting no effect on the early phases of repolarization. In VM, prolongation was measured in all stages of repolarization, from $\mathrm{APD}_{10}$ to $\mathrm{APD}_{90}(p<0.01)$. The prolongation of AP duration in VM was more pronounced than in PFs; thus, $\triangle \mathrm{APD}_{90}$ decreased substantially $(18.0 \pm 5.0 \mathrm{~ms}$ vs. $45.7 \pm 5.7$ $\mathrm{ms}, p<0.01)$. APA and $V_{\max }$ of $\mathrm{VM}$ remained unchanged compared to the control.
$\mathrm{T} 1, \mathrm{~T} 2$

F2-F3 
Fig. 1. Photographs of an electrotonically coupled ventricular preparation. (A) Pacing microelectrode; (B) microelectrode impaled in a Purkinje fiber; (C) microelectrode impaled in a ventricular muscle); (D) an uncoupled papillary muscle; (E) an uncoupled Purkinje fiber inside the tissue bath. [Colour online.]
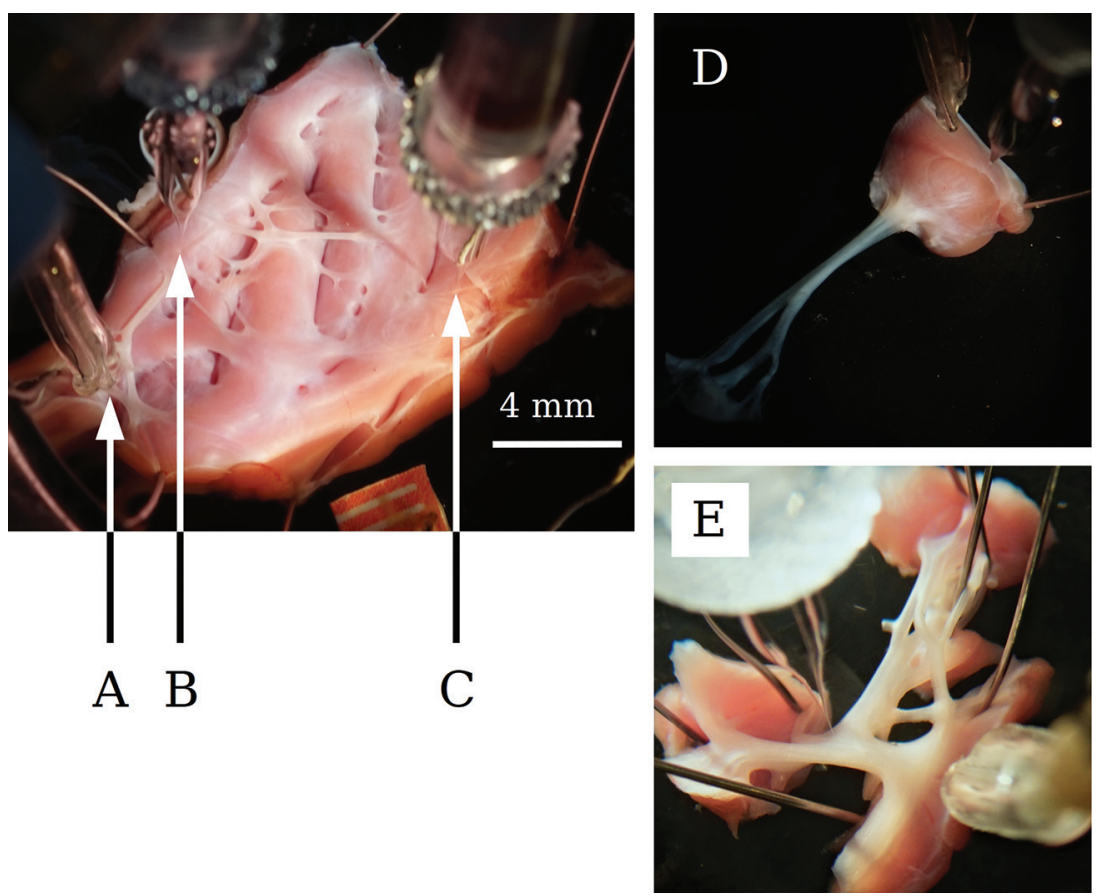

Table 1. The electrophysiological effects of $50 \mathrm{mg} \cdot \mathrm{kg}^{-1} \cdot \mathrm{day}^{-1}$ amiodarone in electrotonically coupled (“C”) Purkinje fiber (PF) and ventriculat muscle (VM) preparations at a basic cycle length of $1000 \mathrm{~ms}$.

\begin{tabular}{lllllllll}
\hline & Sample & $\mathrm{CT}(\mathrm{ms})$ & $\mathrm{RP}(\mathrm{mV})$ & $\mathrm{APA}(\mathrm{mV})$ & $V_{\max }(\mathrm{V} / \mathrm{s})$ & $\mathrm{APD}_{90}(\mathrm{~ms})$ & $\mathrm{APD}_{50}(\mathrm{~ms})$ & $\mathrm{APD}_{90}$ difference $(\mathrm{ms})$ \\
\hline Control & $\mathrm{PF}-\mathrm{C}(14)$ & $5.2 \pm 0.7$ & $-88.4 \pm 3.2$ & $119.2 \pm 2.6$ & $515.6 \pm 43.2$ & $259.8 \pm 5.5$ & $170.9 \pm 5.7$ & $41.0 \pm 5.6$ \\
Amiodarone $\left(50 \mathrm{mg} \cdot \mathrm{kg}^{-1} \cdot \mathrm{day}^{-1}\right)$ & $\mathrm{PF}-\mathrm{C}(11)$ & $4.0 \pm 0.6$ & $-84.6 \pm 2$ & $120.7 \pm 2.8$ & $516.2 \pm 67.2$ & $305.9 \pm 5.8^{\# \# \#}$ & $184.8 \pm 10.9$ & $18.0 \pm 5^{\# \#}$ \\
& VM-C (14) & $13.5 \pm 1.2$ & $-85.8 \pm 1.6$ & $110.1 \pm 2.9$ & $201.3 \pm 27.9$ & $218.8 \pm 7.6$ & $165.0 \pm 5.5$ \\
Amiodarone $\left(50 \mathrm{mg} \cdot \mathrm{kg}^{-1} \cdot \mathrm{day}^{-1}\right)$ & $\mathrm{VM}-\mathrm{C}(11)$ & $12.7 \pm 1.6$ & $-87.8 \pm 2.7$ & $106.8 \pm 3.8$ & $150.4 \pm 46.1$ & $288.0 \pm 5.9^{\# \# \#}$ & $218.2 \pm 7.6^{\# \# \#}$ \\
\hline
\end{tabular}

Note: CT, conduction time; RP, resting potential; APA, action potential amplitude; $V_{\max }$, maximum rate of depolarization; $\mathrm{APD}_{90}$ and $\mathrm{APD} \mathrm{D}_{50}$, action potential durations at $90 \%$ and $50 \%$ of repolarization. Results are means \pm SEM. ${ }^{\# \#} p<0.01,{ }^{\# \# \# p} p<0.001$, Student's $t$ test for unpaired data.

Table 2. The electrophysiological effects of $50 \mathrm{nmol} / \mathrm{L}$ dofetilide in electrotonically coupled (“C”) Purkinje fiber (PF) and ventriculat muscle (VM) preparations at a basic cycle length of $1000 \mathrm{~ms}$.

\begin{tabular}{|c|c|c|c|c|c|c|c|c|}
\hline & Sample & $\mathrm{CT}(\mathrm{ms})$ & $\mathrm{RP}(\mathrm{mV})$ & $\mathrm{APA}(\mathrm{mV})$ & $V_{\max }(\mathrm{V} / \mathrm{s})$ & $\mathrm{APD}_{90}(\mathrm{~ms})$ & $\mathrm{APD}_{50}(\mathrm{~ms})$ & $\mathrm{APD}_{90}$ difference $(\mathrm{ms})$ \\
\hline Control & PF-C (7) & $6.5 \pm 0.9$ & $-90.5 \pm 3.8$ & $123.1 \pm 4.7$ & $369.2 \pm 55$ & $265.0 \pm 4.4$ & $203.4 \pm 4.4$ & $37.0 \pm 4.3$ \\
\hline Dofetilide (50 nmol/L) & PF-C (7) & $7.1 \pm 1.2$ & $-87.4 \pm 3.3$ & $122.2 \pm 5.5$ & $350.4 \pm 51.1$ & $333.9 \pm 8.8^{* * *}$ & $244.6 \pm 8.7^{* * *}$ & $67.2 \pm 10.3^{* *}$ \\
\hline Control & VM-C (7) & $15.4 \pm 0.8$ & $-82.8 \pm 3.7$ & $110.6 \pm 4.5$ & $169.9 \pm 18.5$ & $228.6 \pm 5.7$ & $175.9 \pm 5.6$ & \\
\hline
\end{tabular}

Note: CT, conduction time; RP, resting potential; APA, action potential amplitude; $V_{\max }$, maximum rate of depolarization; $\mathrm{APD}_{90}$ and $\mathrm{APD}_{50}$, action potential durations at $90 \%$ and $50 \%$ of repolarization. Results are means \pm SEM. ${ }^{*} p<0.05,{ }^{* *} p<0.01,{ }^{* * *} p<0.001$, Student's $t$ test for paired data.

In uncoupled $\mathrm{PF}$ preparations, $\mathrm{APD}_{90}$ and $\mathrm{APD}_{75}$ were increased $(p<0.05)$; the prolongation was more pronounced than in coupled preparations (Table 3; Fig. 2D). In uncoupled VM preparations, $\mathrm{APD}_{90}$ and $\mathrm{APD}_{50}$ were also increased $(p<0.01)$, although this change was less pronounced compared to the VM measurements from coupled preparations. These effects reflected an important difference between coupled and uncoupled preparations in response to chronic amiodarone treatment. Accordingly, in uncoupled preparations, amiodarone increased APD without significantly changing dispersion of repolarization between $\mathrm{PF}$ and $\mathrm{VM}$, measured as $\triangle \mathrm{APD}_{90}$. On the contrary, in coupled preparations, amiodarone increased APD in such a manner to result in a significant decrease of dispersion of repolarization, measured as $\triangle \mathrm{APD}_{90}$.

\section{Effects of dofetilide}

In coupled preparations, acutely administered dofetilide ( $n=8$, $50 \mathrm{nM}$ ) induced a marked increase in APD90, APD75 and APD50 $(p<0.001)$ values in PF compared to control measurements (Table 2 , Fig. 3B). In VM, APD90 and APD75 values were also prolonged ( $p<0.01$ and $p<0.05$ respectively), and APD50 was markedly increased. The more pronounced prolongation of AP duration in PFs led to an increase in $\triangle \mathrm{APD} 90$ to $75.2 \pm 12.6 \mathrm{~ms}$ from $47.0 \pm 11.1 \mathrm{~ms}$ 
Fig. 2. The effect of chronic amiodarone $\left(50 \mathrm{mg} \cdot \mathrm{kg}^{-1} \cdot \mathrm{day}^{-1}\right)$ in $(\mathrm{A}$ and $\mathrm{B})$ coupled and $(\mathrm{C}$ and $\mathrm{D})$ uncoupled action potentials. Solid lines represent Purkinje fiber potentials and dotted lines represent ventricular action potentials; stimulation frequency was $1 \mathrm{~Hz}$. [Colour online.]
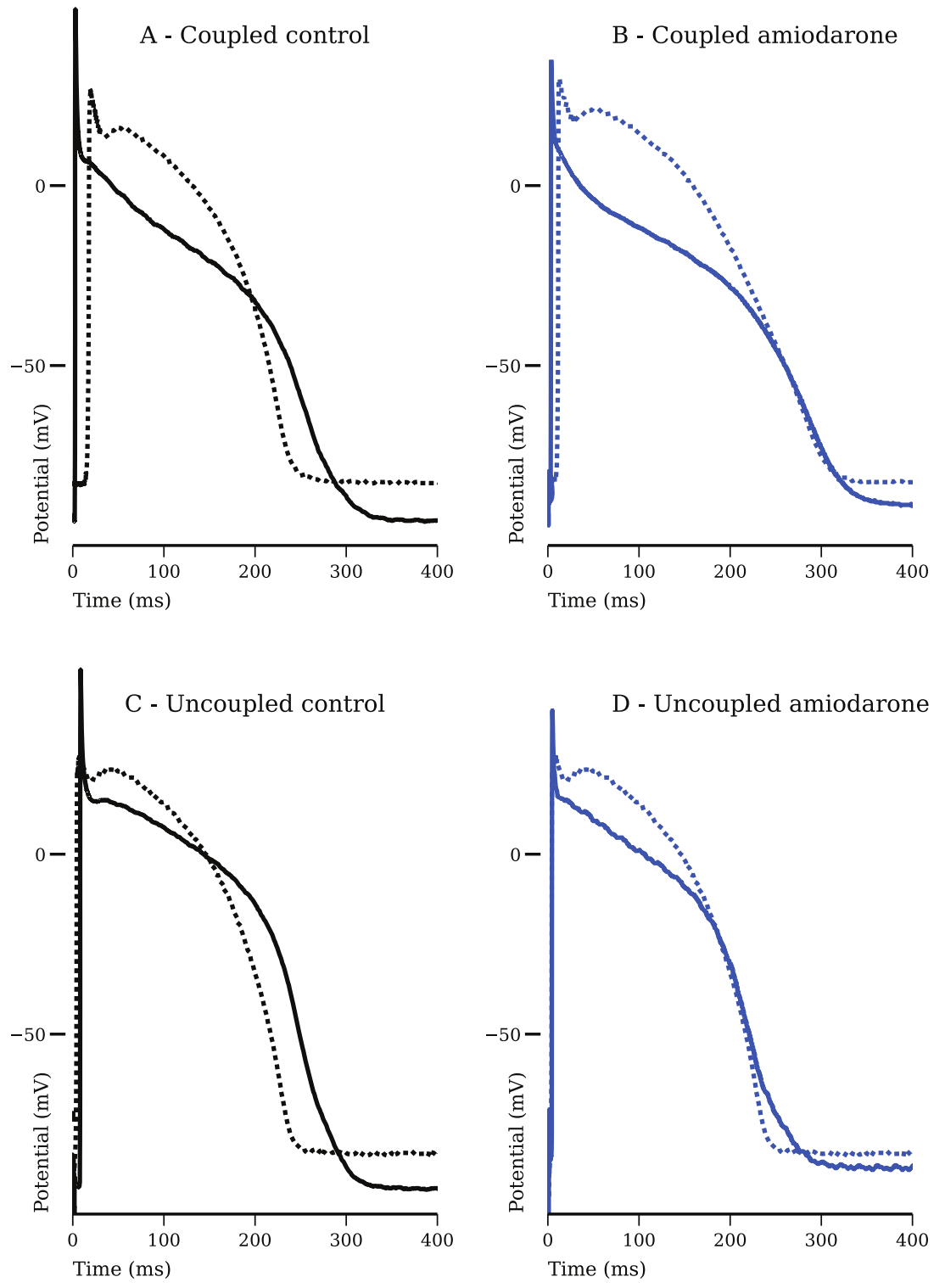

$(p<0.01)$. APA and $V_{\max }$ did not change. Conduction times (CTs) slightly increased after dofetilide treatment.

In uncoupled PF preparations $(n=6-6), \mathrm{APD}_{90}, \mathrm{APD}_{75}$, and $\mathrm{APD}_{50}$ were also prolonged after dofetilide treatment $(p<0.001)$, but prolongation was more pronounced compared to the change in coupled preparations (Table 4; Fig. 3D). In uncoupled VM preparations, $\mathrm{APD}_{90}$ to $\mathrm{APD}_{25}$ were all prolonged after dofetilide treatment $(p<0.01)$. Even though the change in uncoupled VM APD 90 is comparable to that of the coupled preparations, the AP of PFs showed a more pronounced prolongation, unlike with that of amiodarone treatment, indicated by the greatly increased difference in average $\mathrm{APD}_{90}$ values.

\section{Discussion}

Under control conditions, PF APDs were shorter in coupled preparations compared to uncoupled preparations, while VM APDs were longer when coupled with PF, as indicated in the control values of Tables 1 and 2, when compared to those of Tables 3

and 4. APs recorded from canine transitional cells in the PMJs have been previously described to have longer APD than VM and slower maximum rate of depolarization than PF but limited to the immediate surroundings of the PMJ (Martinez-Palomo et al. 1970), suggesting that the slight prolongation we observed in VM and abbreviation in PFs when measured in electrotonically coupled preparations may be attributable to the electrotonic interaction between VM and PFs. This is not the case in dissected ventricular and Purkinje preparations (i.e., individual PFs, papillary muscle, or trabecule). Therefore, these latter preparations are not affected by electrotonic coupling, which also leads to an exaggerated difference in APD; thus, when calculating dispersion from individual, uncoupled preparations, dispersion is likely to be overestimated.

Prolongation of APs in individual VM preparations has been previously reported after chronic amiodarone treatment, while $\mathrm{PF}$ has been not changed or shortened. Thus, the differences in APD have been decreased between PF and VM in uncoupled 
Fig. 3. The effect of dofetilide $(50 \mathrm{nmol} / \mathrm{L})$ in (A and B) coupled and (C and D) uncoupled action potentials. Solid lines represent Purkinje fiber potentials and dotted lines represent ventricular action potentials; stimulation frequency was $1 \mathrm{~Hz}$. [Colour online.]

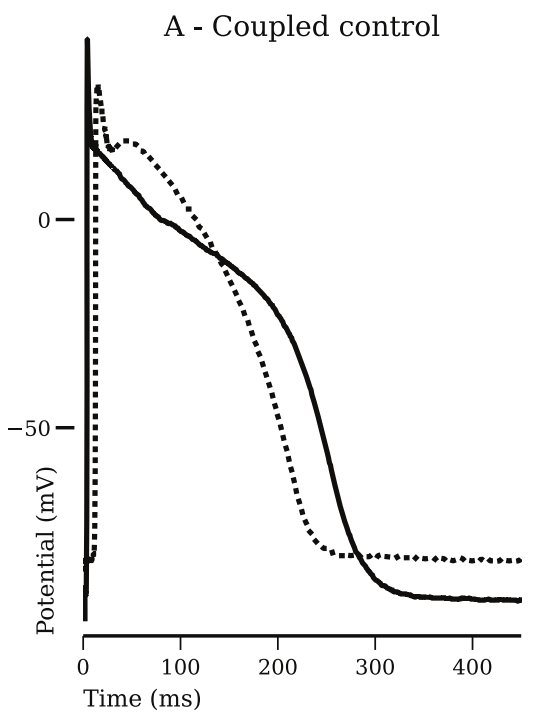

$$
\text { B - Coupled dofetilide }
$$

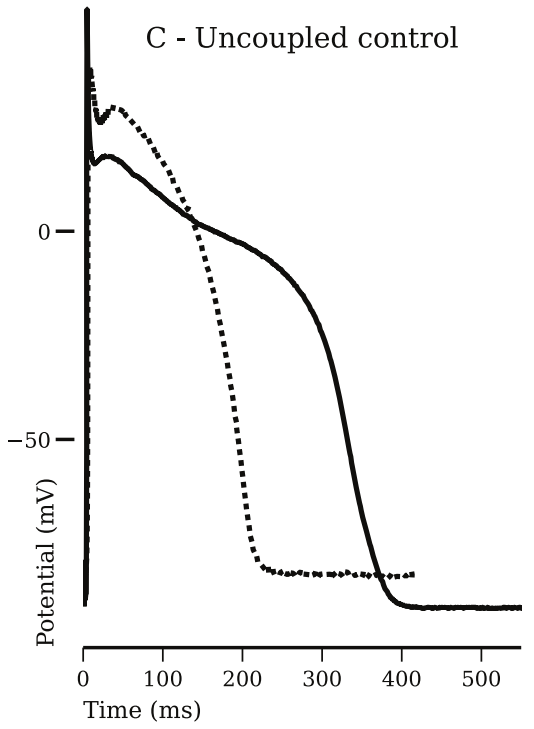

preparations (Papp et al. 1996). In our experiments, amiodarone was found to prolong APD of PF significantly in electrotonically coupled, but not in uncoupled, preparations, as seen in Fig. 2, and in uncoupled preparations resulted in no difference between the $\mathrm{APD}_{90}$ of PFs and VM. However, after chronic amiodarone treatment in electrotonically coupled preparations, we observed slight to moderate prolongation of PF repolarization accompanied by a much more pronounced prolongation of VM, leading to a decrease of dispersion of repolarization, reflected as lower $\triangle \mathrm{APD}_{90}$ (Fig. 4).

The effect of dofetilide in uncoupled cardiac PF and VM preparations is well documented (Gwilt et al. 1991; Knilans et al. 1991; Bányász et al. 2009), but such measurements have not been reported in ex vivo coupled preparations. Therefore, in this study, direct comparison between coupled and uncoupled preparations was possible after dofetilide administration. In coupled preparations, dofetilide increased $\triangle \mathrm{APD}_{90}$ by causing a much greater prolongation in PFs than in VM (Table 2). This difference
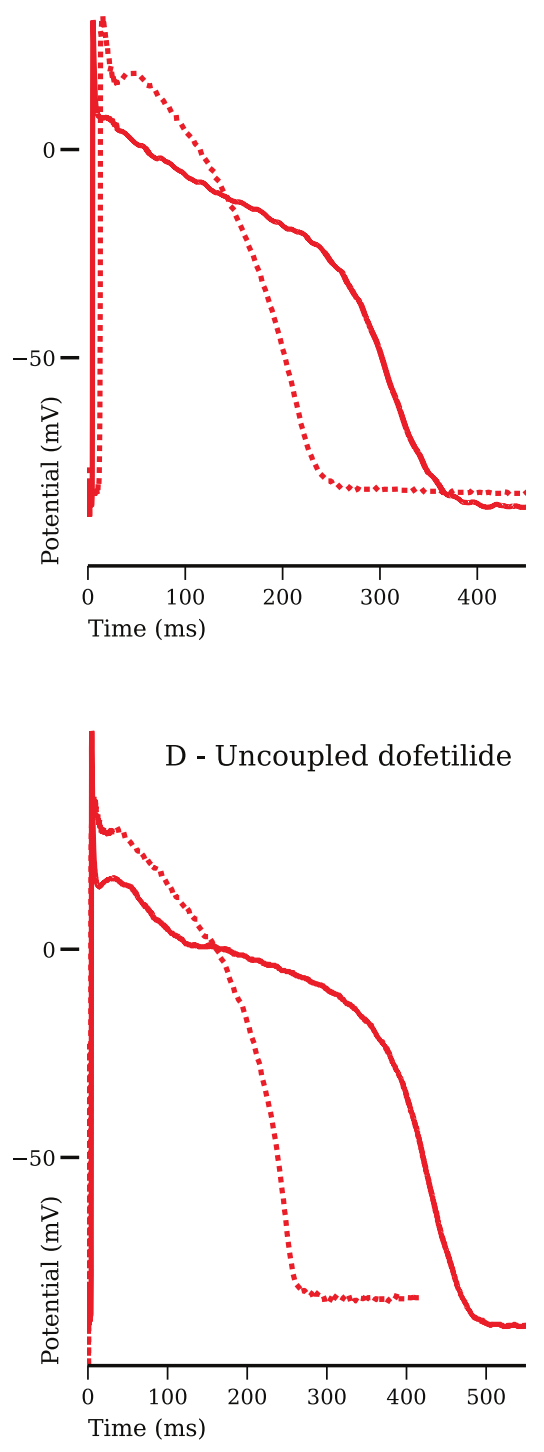

in mean $\mathrm{APD}_{90}$ values was further increased in uncoupled preparations, as seen in Table 4.

The different changes in dispersion may be partially explained by the different effects of each drug on ion channels: dofetilide is considered as a selective inhibitor of the delayed rectifier outward potassium current $\left(I_{\mathrm{Kr}}\right)$ (Carmeliet 1992; Kiehn et al. 1994; Mounsey and DiMarco 2000), while amiodarone also inhibits inward currents, such as $I_{\mathrm{NaL}}$ and $I_{\mathrm{CaL}}$ (Follmer et al.1987; Kodama et al. 1996; Nishimura et al. 1989), and outward currents, such as $I_{\mathrm{Ks}}$, apart from $I_{\mathrm{Kr}}$ (Balser et al. 1991; Bertran et al. 1998; Kodama et al. 1996; Sato et al. 1994; Varró et al. 1996). Since $I_{\mathrm{NaL}}$ is considered more prominent in PFs than in VM (Baláti et al. 1998; Haufe et al. 2005), blocking $I_{\mathrm{NaL}}$ by amiodarone would limit APD lengthening in PFs more than in VM, resulting in less dispersion of repolarization.

In this work, we did not study the possible role of calcium signaling in either tissue type. Nevertheless, it is worth mentioning that in previous studies performed in uncoupled PF and VM 
Table 3. The electrophysiological effects of $50 \mathrm{mg} \cdot \mathrm{kg}^{-1} \cdot \mathrm{day}^{-1}$ amiodarone in uncoupled ("S") Purkinje fiber (PF) and ventricular muscle (VM) preparations at a basic cycle length of $1000 \mathrm{~ms}$.

\begin{tabular}{lllllllll}
\hline & Sample & $\mathrm{CT}(\mathrm{ms})$ & $\mathrm{RP}(\mathrm{mV})$ & $\mathrm{APA}(\mathrm{mV})$ & $V_{\max }(\mathrm{V} / \mathrm{s})$ & $\mathrm{APD}_{90}(\mathrm{~ms})$ & $\mathrm{APD}_{50}(\mathrm{~ms})$ & $\mathrm{APD}_{90}$ difference $(\mathrm{ms})$ \\
\hline Control & PF-S (6) & $5.6 \pm 0.6$ & $-87.6 \pm 1.9$ & $128.6 \pm 4.2$ & $535.7 \pm 42.4$ & $272.3 \pm 16.2$ & $181.9 \pm 9$ & 65.3 \\
Amiodarone $\left(50 \mathrm{mg} \cdot \mathrm{kg}^{-1} \cdot \mathrm{day}^{-1}\right)$ & $\mathrm{PF}-\mathrm{S}(7)$ & $4.1 \pm 0.7$ & $-85.7 \pm 3.7$ & $120.8 \pm 6.1$ & $510.3 \pm 50.9$ & $302.3 \pm 14.6$ & $161.4 \pm 21.2$ & 72.2 \\
Control & VM-S (10) & $6.1 \pm 0.4$ & $-85.8 \pm 0.8$ & $108.2 \pm 3.2$ & $238.9 \pm 30.9$ & $207 \pm 4.4$ & $169.9 \pm 4$ & \\
Amiodarone (50 $\left.\mathrm{mg} \cdot \mathrm{kg}^{-1} \cdot \mathrm{day}^{-1}\right)$ & $\mathrm{VM}-\mathrm{S}(11)$ & $4.6 \pm 0.1^{\# \#}$ & $-84.5 \pm 1.6$ & $101.9 \pm 2.6$ & $173.9 \pm 13.7$ & $230.1 \pm 3.6^{\# \# \#}$ & $180.3 \pm 3.7$ & \\
\hline
\end{tabular}

Note: CT, conduction time; RP, resting potential; APA, action potential amplitude; $V_{\max }$, maximum rate of depolarization; APD $\mathrm{A}_{90}$ and APD $\mathrm{D}_{50}$, action potential durations at $90 \%$ and $50 \%$ of repolarization. Results are means \pm SEM. ${ }^{\# \#} p<0.01,{ }^{\# \# \#} p<0.001$, Student's $t$ test for unpaired data.

Table 4. The electrophysiological effects of $50 \mathrm{nM}$ dofetilide in uncoupled (“S”) Purkinje fiber (PF) and ventricular muscle (VM) preparations at a basic cycle length of $1000 \mathrm{~ms}$.

\begin{tabular}{lllllllll}
\hline & Sample & $\mathrm{CT}(\mathrm{ms})$ & $\mathrm{RP}(\mathrm{mV})$ & $\mathrm{APA}(\mathrm{mV})$ & $V_{\max }(\mathrm{V} / \mathrm{s})$ & $\mathrm{APD}_{90}(\mathrm{~ms})$ & $\mathrm{APD}_{50}(\mathrm{~ms})$ & $\mathrm{APD}_{90}$ difference $(\mathrm{ms})$ \\
\hline Control & PF-S (7) & $5.5 \pm 0.6$ & $-87.2 \pm 1.8$ & $133.5 \pm 2.6$ & $487.3 \pm 42.3$ & $280 \pm 23.5$ & $181.9 \pm 18.5$ & 81.3 \\
Dofetilide $(50 \mathrm{nmol} / \mathrm{L})$ & PF-S (7) & $6.1 \pm 0.8$ & $-88.8 \pm 1.6$ & $134.6 \pm 2.1$ & $446.9 \pm 40.5$ & $409.9 \pm 12^{* * *}$ & $252.7 \pm 9.6^{* * *}$ & 168.1 \\
Control & VM-S (6) & $6.2 \pm 0.9$ & $-86.2 \pm 2.4$ & $116.7 \pm 3.8$ & $192 \pm 20.3$ & $198.7 \pm 3.1$ & $163.8 \pm 3$ \\
Dofetilide (50 nmol/L) & VM-S (6) & $6.3 \pm 0.76$ & $-84.6 \pm 2.5$ & $120.6 \pm 3$ & $195.7 \pm 22.8$ & $241.8 \pm 6.6^{* *}$ & $196.6 \pm 6.3^{* *}$
\end{tabular}

Note: CT, conduction time; RP, resting potential; APA, action potential amplitude; $V_{\max }$, maximum rate of depolarization; APD 90 and APD ${ }_{50}$, action potential durations at $90 \%$ and $50 \%$ of repolarization. Results are means \pm SEM. ${ }^{* *} p<0.01,{ }^{* * *} p<0.001$, Student's $t$ test for unpaired data.

Fig. 4. The action potential differences between Purkinje fibers (PF) and ventricular muscle (VM) in electrotonically coupled and uncoupled preparations during control conditions after chronic amiodarone treatment $\left(50 \mathrm{mg} \cdot \mathrm{kg}^{-1} \cdot \mathrm{day}^{-1}\right)$ and in the presence of dofetilide $(50 \mathrm{nmol} / \mathrm{L})$. Bars represent means \pm SEM. The white areas in the PF bars represent the difference in action potential duration between PF and VM; stimulation frequency was $1 \mathrm{~Hz}$. [Colour online.]
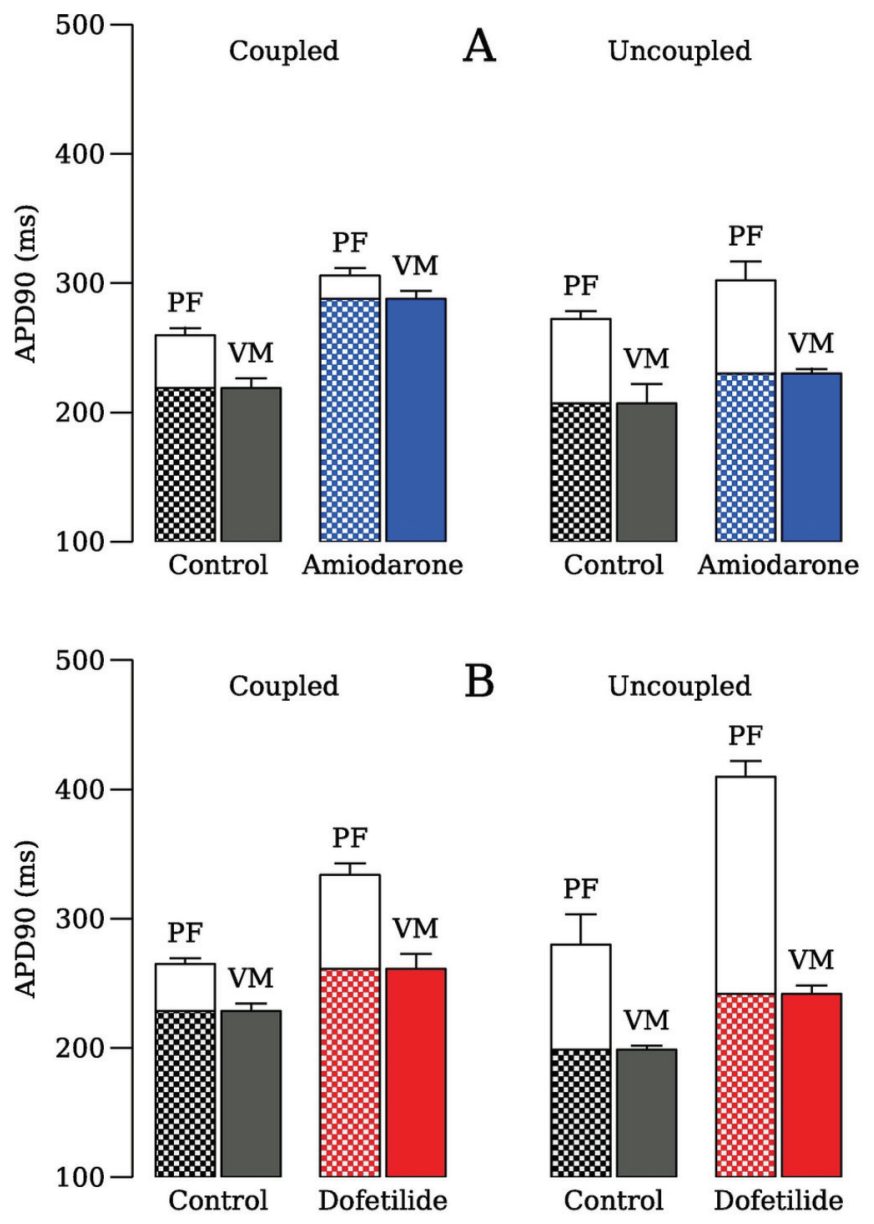

preparations, amiodarone abolished EADs and delayed afterdepolarizations (Varró et al. 2001). On the contrary, several studies have shown that dofetilide evoked EADs in various cardiac preparations (Horváth et al. 2015; Nalos et al. 2012; Fedida et al. 2006). In some preliminary, additional experiments, we found that in coupled preparations, dofetilide evoked EADs only when administered in combination with $\mathrm{CsCl}$ and Bay K8644, i.e., a situation where repolarization reserve had been previously attenuated and calcium current had been activated. Therefore, understanding calcium signaling in electrotonically coupled preparations should be an aim of further studies.

The extent of AP prolongation elicited by each drug also varies between the electronically coupled and uncoupled preparations. Dofetilide elicited a more pronounced prolongation in uncoupled PFs compared to changes measured when coupled with VM. This can be witnessed when comparing Figs. 3B and 3D. PF prolongation caused by chronic amiodarone treatment was similar in coupled and uncoupled conditions, but VM prolongation was more pronounced in coupled preparations (Fig. 4). These differences may be explained by the undisturbed electrotonic coupling between the PFs and the subendocardial VM, since this interaction may lead to a slight decrease in the measured APD of PFs and slight increase in that of VM, partially evening out the distinct difference in APDs measured when the conduction system and the myocardium are dissected. Accordingly, the extent of PF prolongation caused by dofetilide may partially be modulated by the neighboring ventricular muscle, and the prolongation of VM caused by amiodarone may be, in a similar manner, potentiated by the interaction with PFs. Thus, our data from coupled and uncoupled preparations suggest that the electrotonic interaction between PFs and subendocardial myocardium affects not only the baseline electrophysiology of tissues studied using the conventional microelectrode technique but also the measured effects elicited by antiarrhythmic agents.

Therefore, amiodarone ex vivo decreased not only transmural dispersion, previously demonstrated on canine (Sicouri et al. 1997) and human (Drouin et al. 1998) preparations, but also between PFs and VM. In the clinical setting, the QT/QTc prolongation increase is associated with an increased risk of VT/VF. However, drugs that not only increase QT/QTc but also decrease the dispersion of QT/QTc or JT are accompanied by a lower proarrhythmic risk (e.g., amiodarone), while agents that prolong QT/QTc without a decrease in dispersion (e.g., quinidine) have a higher risk of arrhythmic events (Cui et al. 1994; Antzelevitch et al. 1998). It has also been reported that dofetilide increases 
electrical heterogeneity in the human heart (Stabenau et al. 2020). Dofetilide is associated with a higher risk of causing torsades than amiodarone (Brendorp et al. 2002). Amiodarone has also been shown to decrease dispersion of monophasic $\mathrm{APD}_{90}$ (Osaka et al. 2011). The decrease in dispersion between the cardiac conductive system and myocardium may also be a beneficial action of antiarrhythmic agents, similar to the reduction of transmural dispersion, by decreasing the diversity in refractoriness between adjacent cardiac regions, consequently decreasing the risk of extra beats propagating by unidirectional block.

\section{Conclusion}

This study demonstrated that amiodarone, like dofetilide, lengthened cardiac repolarization but unlike dofetilide, it decreased dispersion of repolarization in a preparation that preserves electrotonic coupling between PFs and subendocardial VM. Also, cardiac electrophysiological drug effects can be better established in preparations with preserved electrotonic coupling than in uncoupled tissues. The observed marked differences between the effects of amiodarone and dofetilide on dispersion of repolarization in both well-coupled and uncoupled PFs and VM fibers provide a further explanation why amiodarone has a significantly less proarrhythmic risk than dofetilide, in spite of both drugs exerting a similar degree of QT lengthening in patients. This effect of amiodarone, unlike that of dofetilide, suggests an antiarrhythmic effect without a significant proarrhythmic risk. In addition, this study highlights the importance of studying dispersion of repolarization between PFs and VM in well-coupled preparations, since drug effects can be over- and underestimated in uncoupled preparations.

\section{Acknowledgements}

This work was funded by the National Research Development and Innovation Office (NKFIH K-119992 and GINOP-2.3.2-15-201600048-STAY ALIVE), the Ministry of Human Capacities Hungary (20391-3/2018/FEKUSTRAT, EFOP-3.6.2-16-2017-00006-LIVE LONGER, and EFOP 3.6.3-VEKOP-16-2017-00009), and the Hungarian Academy of Sciences. The GINOP and EFOP projects are cofinanced by the European Union and the European Regional Development Fund.

\section{References}

Antzelevitch, C., Shimizu, W., Yan, G.X., and Sicouri, S. 1998. Cellular basis for QT dispersion. J. Electrocardiol. 30(Suppl): 168-175. doi:10.1016/s00220736(98)80070-8. PMID:9535495.

Baláti, B., Varró, A., and Papp, J.G. 1998. Comparison of the cellular electrophysiological characteristics of canine left ventricular epicardium, M cells, endocardium and Purkinje fibres. Acta Physiol. Scand. 164(2): 181-190. doi:10.1046/j.1365-201X.1998.00416.x. PMID:9805105.

Balser, J.R., Bennett, P.B., Hondeghem, L.M., and Roden, D.M. 1991. Suppression of time-dependent outward current in guinea pig ventricular myocytes. Actions of quinidine and amiodarone. Circ. Res. 69(2): 519-529. doi:10.1161/01.res.69.2.519. PMID:1860189.

Bányász, T., Horváth, B., Virág, L., Bárándi, L., Szentandrássy, N., Harmati, G., et al. 2009. Reverse rate dependency is an intrinsic property of canine cardiac preparations. Cardiovasc. Res. 84(2): 237-244. doi:10.1093/cvr/cvp213. PMID:19556280.

Bertran, G.C., Biagetti, M.O., Valverde, E.R., and Quinteiro, R.A. 1998. Effects of amiodarone and desethylamiodarone on the inward rectifying potassium current (IK1) in rabbit ventricular myocytes. J. Cardiovasc. Pharmacol. 31(6): 914-920. doi:10.1097/00005344-199806000-00016. PMID:9641477.

Brendorp, B., Pedersen, O., Torp-Pedersen, C., Sahebzadah, N., and Køber, L. 2002. A benefit-risk assessment of class III antiarrhythmic agents. Drug Saf. 25(12): 847-865. doi:10.2165/00002018-200225120-00003. PMID:12241126.

Carmeliet, E. 1992. Voltage- and time-dependent block of the delayed K+ current in cardiac myocytes by dofetilide. J. Pharmacol. Exp. Ther. 262(2): 809-817. PMID:1501123.

Cui, N., Sager, N., Singh, N., and Sen, N. 1998. Different effects of amiodarone and quinidine on the homogeneity of myocardial refractoriness in patients with intraventricular conduction delay. J. Cardiovasc. Pharmacol. Ther. 3(3): 201-208. doi:10.1177/107424849800300301. PMID:10684498.
Cui, G., Sen, L., Sager, P., Uppal, P., and Singh, B.N. 1994. Effects of amiodarone, sematilide, and sotalol on QT dispersion. Am. J. Cardiol. 74(9): 896900. doi:101016/0002-9149(94)90582-7. PMID:7526675.

Drouin, E., Lande, G., and Charpentier, F. 1998. Amiodarone reduces transmural heterogeneity of repolarization in the human heart. J. Am. Coll. Cardiol. 32(4): 1063-1067. doi:10.1016/s0735-1097(98)00330-1. PMID:9768733.

Fedida, D., Orth, P.M.R., Hesketh, J.C., and Ezrin, A.M. 2006. The role of late I and antiarrhythmic drugs in EAD formation and termination in Purkinje fibers. J. Cardiovasc. Electrophysiol. 17(s1): S71-S78. doi:10.1111/j.1540-8167.2006.00386.x. PMID:16686685.

Follmer, C.H., Aomine, M., Yeh, J.Z., and Singer, D.H. 1987. Amiodaroneinduced block of sodium current in isolated cardiac cells. J. Pharmacol. Exp. Ther. 243(1): 187-194. PMID:2444698.

Gilmour, R.F., and Watanabe, M. 1994. Dynamics of circus movement reentry across canine Purkinje fibre-muscle junctions. J. Physiol. 476(3): 473-485. doi:10.1113/jphysiol.1994.sp020148. PMID:8057255.

Glukhov, A.V., Fedorov, V.V., Lou, Q., Ravikumar, V.K., Kalish, P.W., Schuessler, R.B., et al. 2010. Transmural dispersion of repolarization in failing and nonfailing human ventricle. Circ. Res. 106(5): 981-991. doi:10.1161/CIRCRESAHA.109.204891. PMID:20093630.

Gwilt, M., Arrowsmith, J.E., Blackburn, K.J., Burges, R.A., Cross, P.E., Dalrymple, H.W., and Higgins, A.J. 1991. UK-68,798: a novel, potent and highly selective class III antiarrhythmic agent which blocks potassium channels in cardiac cells. J. Pharmacol. Exp. Ther. 256(1): 318-324. PMID: 1988662

Haufe, V., Cordeiro, J.M., Zimmer, T., Wu, Y.S., Schiccitano, S., Benndorf, K., and Dumaine, R. 2005. Contribution of neuronal sodium channels to the cardiac fast sodium current INa is greater in dog heart Purkinje fibers than in ventricles. Cardiovasc. Res. 65(1): 117-127. doi:10.1016/j.cardiores.2004.08.017. PMID:15621039.

Horváth, B., Hegyi, B., Kistamás, K., Váczi, K., Bányász, T., Magyar, J., et al. 2015. Cytosolic calcium changes affect the incidence of early afterdepolarizations in canine ventricular myocytes. Can. J. Physiol. Pharmacol. 93(7): 527-534. doi:10.1139/cjpp-2014-0511. PMID:25928391.

Jost, N., Virág, L., Bitay, M., Takács, J., Lengyel, C., Biliczki, P., et al. 2005. Restricting Excessive Cardiac Action Potential and QT Prolongation. Circulation, 112(10): 1392-1399. doi:10.1161/CIRCULATIONAHA.105.550111. PMID:16129791.

Kiehn, J., Villena, P., Beyer, T., and Brachmann, J. 1994. Differential effects of the new class III agent dofetilide on potassium currents in guinea pig cardiomyocytes. J. Cardiovasc. Pharmacol. 24(4): 566-572. doi:10.1097| 00005344-199410000-00007. PMID:7528839.

Knilans, T.K., Lathrop, D.A., Nánási, P.P., Schwartz, A., and Varró, A. 1991. Rate and concentration-dependent effects of UK-68,798, a potent new class III antiarrhythmic, on canine Purkinje fibre action potential duration and $V_{\max }$. Br. J. Pharmacol. 103(2): 1568-1572. doi:10.1111/j.1476-5381. 1991.tb09828.x. PMID:1884111.

Kodama, I., Kamiya, K., Honjo, H., and Toyama, J. 1996. Acute and chronic effects of amiodarone on mammalian ventricular cells. Jpn. Heart J. 37(5): 719-730. doi:10.1536/ihj.37.719. PMID:8973384.

Lengyel, C., Iost, N., Virág, L., Varró, A., Lathrop, D.A., and Papp, J.G. 2001. Pharmacological block of the slow component of the outward delayed rectifier current (IKs) fails to lengthen rabbit ventricular muscle QTc and action potential duration. Br. J. Pharmacol. 132(1): 101-110. doi:10.1038/sj. bjp.0703777. PMID:11156566.

Martinez, M.E., Walton, R.D., Bayer, J.D., Haïssaguerre, M., Vigmond, E.J., Hocini, M., and Bernus, O. 2018. Role of the purkinje-muscle junction on the ventricular repolarization heterogeneity in the healthy and ischemic ovine ventricular myocardium. Front. Physiol. 9: 718. doi:10.3389/fphys.2018.00718. PMID:29962961.

Martinez-Palomo, A., Alanis, J., and Benitez, D. 1970. Transitional cardiac cells of the conductive system of the dog heart. Distinguishing morphological and electrophysiological features. J. Cell Biol. 47(1): 1-17. doi:10.1083/jcb.47.1.1. PMID:5513552.

Mounsey, J.P., and DiMarco, J.P. 2000. Dofetilide. Circulation, 102(21): 26652670. doi:10.1161/01.CIR.102.21.2665. PMID:11085972.

Nalos, L., Varkevisser, R., Jonsson, M.K.B., Houtman, M.J.C., Beekman, J.D., van der Nagel, R., et al. 2012. Comparison of the IKr blockers moxifloxacin, dofetilide and E-4031 in five screening models of pro-arrhythmia reveals lack of specificity of isolated cardiomyocytes. Br. J. Pharmacol. 165(2): 467-478. doi:10.1111/j.1476-5381.2011.01558.x. PMID:21718297.

Nattel, S., and Quantz, M.A. 1988. Pharmacological response of quinidine induced early afterdepolarisations in canine cardiac Purkinje fibres: insights into underlying ionic mechanisms. Cardiovasc. Res. 22(11): 808817. doi:10.1093/cvr/22.11.808. PMID:3256422.

Nishimura, M., Follmer, C.H., and Singer, D.H. 1989. Amiodarone blocks calcium current in single guinea pig ventricular myocytes. J. Pharmacol. Exp. Ther. 251(2): 650-659. PMID:2553932.

Nogami, A. 2011a. Purkinje-related arrhythmias Part I: Monomorphic ventricular tachycardias. Pacing Clin. Electrophysiol. 34(5): 624-650. doi:10.1111/j.15408159.2011.03044.x. PMID:21410719.

Nogami, A. 2011b. Purkinje-related arrhythmias Part II: Polymorphic ventricular tachycardia and ventricular fibrillation. Pacing Clin. Electrophysiol. 34(8): 1034-1049. doi:10.1111/j.1540-8159.2011.03145.x. PMID:21671950.

Orvos, P., Kohajda, Z., Szlovák, J., Gazdag, P., Árpádffy-Lovas, T., Tóth, D., et al. 2019. Evaluation of possible proarrhythmic potency: comparison of . 
the effect of dofetilide, cisapride, sotalol, terfenadine, and verapamil on hERG and native IKr currents and on cardiac action potential. Toxicol. Sci. 168(2): 365-380. doi:10.1093/toxsci/kfy299. PMID:30561737.

Osaka, T., Yokoyama, E., Hasebe, H., and Kodama, I. 2011. Effects of chronic amiodarone on the electrical restitution in the human ventricle with reference to its antiarrhythmic efficacy. J. Cardiovasc. Electrophysiol. 22(6): 669-676. doi:10.1111/j.1540-8167.2010.01990.x. PMID:21235669.

Papp, J.G., Németh, M., Krassói, I.I., Mester, L., Hála, O., and Varró, A. 1996. Differential electrophysiologic effects of chronically administered amiodarone on canine purkinje fibers versus ventricular muscle. J. Cardiovasc. Pharmacol. Ther. 1(4): 287-296. doi:10.1177/107424849600100404. PMID: 10684429.

Sato, R., Koumi, S., Singer, D.H., Hisatome, I., Jia, H., Eager, S., and Wasserstrom, J.A. 1994. Amiodarone blocks the inward rectifier potassium channel in isolated guinea pig ventricular cells. J. Pharmacol. Exp. Ther. 269(3): 1213-1219. PMID:8014865.

Sicouri, S., Moro, S, Litovsky, S, Elizari, MV, and Antzelevitch, C. 1997. Chronic amiodarone reduces transmural dispersion of repolarization in the canine heart. J. Cardiovasc. Electrophysiol. 8(11): 1269-1279. doi:10.1111/j.15408167.1997.tb01018.x. PMID:9395170.
Stabenau, H.F., Shen, C., Tereshchenko, L.G., and Waks, J.W. 2020. Changes in global electrical heterogeneity associated with dofetilide, quinidine, ranolazine, and verapamil. Heart Rhythm, 17(3): 460-467. doi:10.1016/j. hrthm.2019.09.017. PMID:31539628.

Varró, A., Lathrop, D.A., and Surawicz, B. 1990. Effects of propranolol on premature action potentials in canine Purkinje and ventricular muscle. J. Cardiovasc. Pharmacol. 16(5): 757-763. doi:10.1097/00005344-19901100000010. PMID:1703597.

Varró, A., Takács, J., Németh, M., Hála, O., Virág, L., Iost, N., et al. 2001. Electrophysiological effects of dronedarone (SR 33589), a noniodinated amiodarone derivative in the canine heart: comparison with amiodarone. Br. J. Pharmacol. 133(5): 625-634. doi:10.1038/sj.bjp.0704106. PMID:11429385.

Varró, A., Virág, L., and Papp, J.G. 1996. Comparison of the chronic and acute effects of amiodarone on the calcium and potassium currents in rabbit isolated cardiac myocytes. Br. J. Pharmacol. 117(6): 1181-1186. doi:10.1111/j.1476-5381.1996.tb16713.x. PMID:8882613.

Walton, R.D., Martinez, M.E., Bishop, M.J., Hocini, M., Haïssaguerre, M., Plank, G., et al. 2014. Influence of the Purkinje-muscle junction on transmural repolarization heterogeneity. Cardiovasc. Res. 103(4): 629-640. doi:10.1093/cvr/cvu165. PMID:24997066. 